\title{
Down-Regulation of miR-183 Promotes Migration and Invasion of Osteosarcoma by Targeting Ezrin
}

\author{
Junfeng Zhu, ${ }^{*}$ Yupeng Feng, ${ }^{\dagger}$ Zunfu Ke, ${ }^{* \neq}$ \\ Zheng Yang, ${ }^{* \ddagger}$ Junyi Zhou, ${ }^{\text {ๆ Xiaorong Huang, }}$ \\ and Liantang Wang ${ }^{\star \ddagger}$ \\ From the Department of Pathology, * First Affiliated Hospital of \\ Sun Yat-Sen University, Guangzhou, Guangdong; the \\ Department of Urinary Surgery, ${ }^{\dagger}$ Affiliated Xixiang People's \\ Hospital of Guangdong Medical College, Shenzhen, Guangdong; \\ and the Departments of Pathology $y^{\ddagger}$ and Biochemistry and \\ Molecular Biology, "Zhongshan School of Medicine, Sun Yat-Sen \\ University, Guangzhou, Guangdong, China
}

Recent studies have emphasized causative links between aberrant microRNA expression patterns and cancer progression. miR-183 is dysregulated in certain types of human cancers. The expression pattern, clinical significance, and biological role of miR-183 in osteosarcoma, however, remain largely undefined. In this paired analysis, we found that miR-183 was markedly down-regulated in osteosarcoma cells and tissues compared with matching normal bone tissues using RT-qPCR. Statistical analyses revealed that the expression levels of miR-183 significantly correlated with lung metastasis as well as with local recurrence of osteosarcoma. miR-183 expression was inversely correlated with Ezrin mRNA and protein expression levels in osteosarcoma cells as well as in a subset of primary osteosarcoma. Ectopically expressed miR183 inhibited migratory and invasive abilities of osteosarcoma cells, whereas knockdown of endogenous miR-183 significantly enhanced these abilities. Using a luciferase reporter carrying the $3^{\prime}$-untranslated region ( $3^{\prime}$-UTR) of Ezrin, we identified Ezrin as a direct target of miR-183. Moreover, ectopic expression of Ezrin could significantly rescue miR-183-suppressed migration and invasion. Of interest, suppression of Ezrin by miR-183 caused a reduction of phosphorylated p44/42 (p-p44/42). Finally, suppression of Ezrin by RNAi mimicked miR-183 action in the suppression of migration and invasion, which was associated with down-regulation of $p-p 44 / 42$. Taken together, these results suggest that as a tumor suppressor miRNA, miR-183 plays an important role in the aggressiveness of osteosarcoma. (Am J Pathol 2012, 180:2440-2451; http://dx.doi.org/10.1016/j.ajpath.2012.02.023)

Osteosarcoma is the most common primary tumor of the bone and is characterized by a highly malignant tendency to rapidly destroy the surrounding tissues and to metastasize. Osteosarcoma frequently localizes to the distal femur and proximal tibia region, and its 5-year survival rate is nearly $70 \% .^{1}$ Pulmonary metastasis is the main cause of death in patients with osteosarcoma. The clinical outcome is extremely poor when patients develop recurrent or metastatic osteosarcoma. ${ }^{2}$ The most important prognostic factor of osteosarcoma is the presence or absence of metastasis. ${ }^{3}$ About $20 \%$ of patients present with metastatic disease and have an extremely poor prognosis, with a long-term survival of less than $10 \% .{ }^{4}$ Despite aggressive chemotherapy and surgery, approximately one-third of all patients with lung metastases have significantly reduced survival. Although many attempts have been made to distinguish patients with a high risk of developing recurrence or metastases from patients with a low risk, ${ }^{5}$ to date, no genetic or molecular prognostic factor can be routinely used. The identification of novel molecules variably expressed in osteosarcoma cells may provide insight into the mechanisms of tumor progression and may serve as prognostic factor of osteosarcoma.

MicroRNAs, an abundant class of endogenous, small noncoding RNAs that are 19 to 25 nucleotides in length, silence target gene expression through either perfect or imperfect binding to their $3^{\prime}$-untranslated region (3'UTR), in turn triggering mRNA (mRNA) degradation or translational repression. A large body of evidence implicates miRNA deregulations in cancer, highlighting their poten-

Supported by Foundation of China National Science (number 81172232/ H1615 and 30900650/H1615); Guangzhou city science and technology project (number 2010 u 1- E 00621).

Accepted for publication February 2, 2012

Supplemental material for this article can be found at http://ajp. amjapthol.org or at $h$ ttp://dx.doi.org/10.1016/j.ajpath.2012.02.023.

Address reprint requests to Liantang Wang, M.D., Ph.D., Department of Pathology, the First Affiliated Hospital of Sun Yat-sen University, 58 Zhongshan Road 2nd, Guangzhou, Guangdong, 510080, China. E-mail: wangltb|@163.com. 
Table 1. Clinicopathological Parameters in Osteosarcoma Cases

\begin{tabular}{|c|c|c|c|c|}
\hline Variable & Cases $(n)$ & $\%$ & $\begin{array}{c}\text { Expression level } \\
\text { of miR-183 }\end{array}$ & $P$ value \\
\hline \multicolumn{5}{|l|}{ Age (years) } \\
\hline$<20$ & 19 & 70.37 & $-10.28 \pm 0.41$ & \multirow{3}{*}{0.866} \\
\hline$\geq 20$ & 8 & 29.63 & $-10.16 \pm 0.51$ & \\
\hline Age (years) at diagnosis & 8-43 (Median age: 17) & & & \\
\hline \multicolumn{5}{|l|}{ Sex } \\
\hline Male & 18 & 66.67 & $-10.44 \pm 0.40$ & \multirow[t]{2}{*}{0.403} \\
\hline Female & 9 & 33.33 & $-9.86 \pm 0.54$ & \\
\hline \multicolumn{5}{|l|}{ Location } \\
\hline Femur & 12 & 44.44 & $-10.31 \pm 0.51$ & \multirow[t]{5}{*}{0.977} \\
\hline Tibia & 6 & 22.22 & $-10.56 \pm 0.90$ & \\
\hline Fibula & 4 & 14.81 & $-9.95 \pm 0.94$ & \\
\hline Humerus & 3 & 11.11 & $-10.00 \pm 0.41$ & \\
\hline Ilium & 2 & 7.41 & $-9.88 \pm 0.39$ & \\
\hline \multicolumn{5}{|l|}{ Histology } \\
\hline Osteoblastic & 22 & 81.48 & $-10.09 \pm 0.33$ & \multirow[t]{2}{*}{0.321} \\
\hline Chondroblastic & 5 & 18.52 & $-10.92 \pm 0.95$ & \\
\hline \multicolumn{5}{|l|}{ Surgery } \\
\hline Amputation & 20 & 74.07 & $-10.17 \pm 0.36$ & \multirow[t]{2}{*}{0.702} \\
\hline Limb salvage & 7 & 25.93 & $-10.46 \pm 0.73$ & \\
\hline \multicolumn{5}{|l|}{ Metastasis or recurrence } \\
\hline Yes & 17 & 62.96 & $-10.73 \pm 0.43$ & \multirow[t]{2}{*}{$0.048 *$} \\
\hline No & 10 & 37.04 & $-9.43 \pm 0.34$ & \\
\hline
\end{tabular}

${ }^{\star} P<0.05$.

tial as diagnostic, prognostic, and therapeutic tools in most human malignancies. ${ }^{6,7}$ Increasing numbers of miRNAs have been implicated in the regulation of cancer metastasis, ${ }^{8}$ including miR-9, ${ }^{9}$ miR-10b, ${ }^{10}$ miR- $145,{ }^{11}$ miR-193b, ${ }^{12}$ and miR-205 in breast cancer ${ }^{13}$; miR-200 in lung adenocarcinoma ${ }^{14}$; miR-146a in pancreatic can$\mathrm{cer}^{15}$; miR-200 in prostate cancer ${ }^{16}$; miR-218 in gastric cancer ${ }^{17}$; miR-335 in malignant astrocytoma ${ }^{18}$; miR-21 in colorectal cancer ${ }^{19}$; and miR-143 in osteosarcoma metastasis. ${ }^{20}$ miR-183 is up-regulated in colorectal cancer ${ }^{21}$ and functions as an oncomiR by targeting the transcription factor EGR1 and promoting tumor cell migration. ${ }^{22}$ However, other studies showed that miR-183 was downregulated in several types of tumors, suggesting its tumor suppression role in inhibiting the invasion of these cancer cells. ${ }^{23,24}$ It has also been reported that miR-183 could inhibit cell migration by targeting ITGB1 in neurosensory organs. ${ }^{25}$ In addition, miR-183 is able to target PDCD4 and to inhibit TGF- $\beta 1$-induced apoptosis in human hepatocellular carcinoma cells. ${ }^{26}$ These investigations indicate the important roles of miR-183 in tumor initiation and progression; however, the biological role of miR-183 in osteosarcoma pathogenesis is still largely unknown.

In the present study, we found that miR-183 expression was markedly down-regulated in osteosarcoma, and that down-regulation of miR-183 was significantly correlated with lung metastasis and local recurrence of osteosarcoma. Furthermore, we identified Ezrin as a target of miR-183 in osteosarcoma cells. Functional analysis showed that down-regulation of miR-183 in osteosarcoma resulted in increased levels of Ezrin and the activation of $p-p 44 / 42$, leading to increased cell migration and invasion. Taken together, our findings support miR183 as a tumor suppressor miRNA in the inhibition of the aggressiveness of osteosarcoma, which suggest that miR-183 is a novel therapeutic target for osteosarcoma.

\section{Materials and Methods}

\section{Clinical Samples and Clinical Characteristics}

A total of 50 cases of archived formalin-fixed, paraffinembedded (FFPE), wide resection of primary osteosarcoma specimens were analyzed. All cases had been clinically and histopathologically diagnosed at the First Affiliated Hospital of Sun Yat-Sen University (Guangzhou, China) from January 2000 to October 2009. The histology of the disease was determined according to the criteria of the World Health Organization. Ethical approval of the study was obtained from the Institutional Research Ethics Committee.

Among 27 cases, 10 had paired non-tumor bone tissues, nine had paired lung metastasis, seven had paired local recurrences, and one had both paired non-tumor bone tissues and lung metastasis. Detailed clinical data of these cases, including the age, sex, location, histological type, surgical method, and metastasis status, are summarized in Table 1. Another 23 cases diagnosed with metastatic-free osteosarcoma were paired with biopsy specimens without preoperative chemotherapy. All of the 23 patients received biopsy before any treatment and they underwent the same neoadjuvant chemotherapy by doxorubicin (ADM), cisplatin (CDP), ifosfamide (IFO), and methotrexate (MTX). All drugs were given intravenously. After preoperative chemotherapy, the patients underwent wide resection of tumor (limb salvage or amputation). Clinicopathologic data such as the age, sex, location, histological type, and surgical method are shown in Table 2. The purity in sections adjacent to the regions used for RNA extraction and immunohistochemistry analysis was validated through routine histopathological analysis. Four fresh samples of primary osteosarcoma and paired non-tumor bone tissues from surgery 
Table 2. Clinicopathological Parameters of Osteosarcoma Cases with Biopsy Results

\begin{tabular}{lrr}
\hline \multicolumn{1}{c}{ Variable } & Cases $(n)$ & $\%$ \\
\hline Age (years) & & \\
$\quad<20$ & 15 & 65.22 \\
$\geq 20$ & 8 & 34.78 \\
Age (years) at diagnosis & & \\
Sex & & \\
$\quad$ Male & 17 & 73.91 \\
$\quad$ Female & 6 & 26.09 \\
Site & 10 & \\
Femur & 5 & 43.48 \\
Tibia & 4 & 21.74 \\
Fibula & 3 & 17.39 \\
Humerus & 1 & 13.04 \\
Ilium & & 4.35 \\
Histology & 17 & 73.91 \\
$\quad$ Osteoblastic & 5 & 21.74 \\
$\quad$ Chondroblastic & 1 & 4.35 \\
Others & & \\
Surgery & 6 & 26.09 \\
$\quad$ Amputation & 17 & 73.91 \\
$\quad$ Limb salvage & & \\
\hline
\end{tabular}

resection were frozen and stored at $-80^{\circ} \mathrm{C}$ for $\mathrm{RNA}$ extraction.

\section{Cell Lines and Transfection}

Osteosarcoma cell lines MG63, U2OS, Saos2, HOS, and SV40 immortalized human fetal osteoblastic cell line hFOB 1.19 (kept in our laboratory) were grown in RPMI1640 medium supplemented with $10 \%$ fetal bovine serum (FBS; Hy-Clone, Logan, UT). The osteoblastic cell line hFOB1.19 was maintained in Dulbecco's modified Eagle's minimal essential medium (DMEM)/F12 (GIBCO, Carlsbad, CA) medium supplemented with 10\% FBS. All cells were harvested at log phrase. The miRNAs and siRNAs were purchased from GenePharm (Shanghai, China) and transfected into the cells using Lipofectamine 2000 (Invitrogen, Carlsbad, CA) according to the manufacturer's protocol.

\section{Isolation of Invasive and Noninvasive Cell Sublines Using Transwell Chambers}

Subpopulations with high or low invasion potential were isolated from MG63 and Saos2 cell lines using 24-well polycarbonate transwell membrane inserts coated with $30 \mathrm{mg} / \mathrm{cm}^{2}$ of Matrigel (8- $\mu \mathrm{m}$ pore size; BD Biosciences, San Jose, CA) as described previously. ${ }^{17,27,28}$ Cells were resuspended to a density of $5 \times 10^{5} / \mathrm{mL}$ in serum-free RPMI-1640 medium. A $300-\mu$ cell suspension was seeded into the inserts, and the lower well beneath the polycarbonate membranes was filled with $900 \mu$ l of RPMI1640 medium supplemented with $10 \%$ FBS to create a chemotactic gradient. Following incubation for 36 hours at $37^{\circ} \mathrm{C}$, the inserts were removed. The invasive cells on the underside of the membrane and the noninvasive cells on the top of the membrane were harvested aseptically and expanded for next-round selection. After 10-round selection, the cell subline that failed to invade through the membranes was designated as MG63-L and Saos2-L, and the subline that was able to migrate through the membranes was designated as MG63-H and Saos2-H.

\section{Total RNA Extraction and Quantitative RT-PCR}

Total RNA was extracted from osteosarcoma cells and frozen tissues by using TRIZOL Reagent (Invitrogen) and from FFPE cells using RecoverAll Total Nucleic Acid Isolation kit (Ambion, Cambridgeshire, UK). Quantitative RTPCR was performed to detect the expression levels of miRNA and mRNA. For Ezrin mRNA detection, reverse transcription was performed using PrimeScript RT Master Mix (Perfect Real Time, TaKaRa, Dalian, China), and qPCR was performed using SYBR Premix Ex Taq II (Tli RNaseH Plus) (TaKaRa) in LightCycler 480 (Roche Diagnostics, Indianapolis, IN). $\beta$-Actin mRNA levels were used for normalization. For miRNAs detection, reverse transcription was performed using One Step PrimeScript miRNA cDNA Synthesis Kit (Perfect Real Time, TaKaRa), and quantitative PCR was performed using SYBR Premix Ex Taq II (Perfect Real Time, TaKaRa). U6 snRNA levels were used for normalization. Forward and reverse primers for Ezrin (76 bp) and $\beta$-actin (88 bp) were 5'-AGAAAGAGCAGATGATGCGCGAGA-3' and 5'-AGGAGGGCA ATCTTGGCTGTGTAT-3', 5'-GGCCGAGGACTTTGATTG CACATT-3' and 5'-AGGATGGCAAGGGACTTCCTGTAA3', respectively. The specific forward primer of miR-183 was as follows: 5'-CGGTATGGCACTGGTAGAATT CACT-3'. Forward and reverse primers for U6 (86 bp) were 5'-CTCGCTTCGGCAGCACATATACTA-3' and 5'ACGAATTTGCGTGTCATCCTTGCG-3'. The quantitative RT-PCR results were analyzed and expressed as relative miRNA or mRNA levels of the CT (cycle threshold) value, which was then converted to fold change.

\section{Western Blot}

Cells were lysed in RIPA buffer containing $50 \mathrm{mmol} / \mathrm{L}$ Tris, $\mathrm{pH} 8.0,150 \mathrm{mmol} / \mathrm{L}$ sodium chloride, 1.0\% Triton $\mathrm{X}-100$ $(\mathrm{v} / \mathrm{v}), 0.5 \%$ sodium deoxycholate, and $0.1 \%$ SDS (w/v), agitated for 30 minutes at $4^{\circ} \mathrm{C}$, and centrifuged at $12,000 \times g$ for 15 minutes. The concentration of total proteins was determined using BCA. Total proteins (25 $\mu \mathrm{g}$ ) in equal volume of $2 X$ LaemmLi buffer were then denatured and subjected to $12 \%$ SDS-PAGE. The proteins were transferred onto acetyl cellulose membranes that were subsequently blocked in 5\% nonfat milk in TBST (20 mmol/L Tris, pH 7.6, 137 mmol/L NaCL, 0.1\% Tween-20). The membranes were incubated with primary antibodies including mouse anti-Ezrin (1:500; ab4069; Abcam, Cambridge, MA), rabbit anti-AKT (1:1000), rabbit anti-phospho-AKT (Ser473) (1:1000), rabbit anti-p44/42 MAPK (Erk1/2) (1:1000), rabbit anti-phospho-p44/42 MAPK (Erk1/2) (Thr202/Tyr204) (1:2000), and rabbit anti$\beta$-actin (1:2000) (Cell Signaling Technology, Danvers, $\mathrm{MA})$ at $4^{\circ} \mathrm{C}$ overnight. After washing, the membranes were incubated with secondary antibody HRP-conjugated goat anti-mouse (1:5000 dilution; Cell Signaling Technology) or goat anti-rabbit (1:5000 dilution; Invitrogen) and visualized by enhanced chemiluminescence. 


\section{Immunohistochemistry}

Immunohistochemical staining for Ezrin was performed on formalin-fixed, paraffin-embedded tissue sections of osteosarcoma. Antigen retrieval was performed using Tris-EDTA Buffer $(10 \mathrm{mmol} / \mathrm{L}$ Tris base, $1 \mathrm{mmol} / \mathrm{L}$ EDTA solution, $0.05 \%$ Tween $20, \mathrm{pH}$ 9.0) and the microwave method. The tissues were incubated with mouse antiEzrin (ab4069; Abcam) monoclonal antibodies, at dilution of 1:50 at room temperature for 30 minutes. The tissues were then stained using the EnVision Detection Kit, peroxidase/DAB, Rabbit/Mouse (Genetech, Shanghai, China). Immunohistochemical score was expressed according to a semiquantitative scale based on the following criteria ${ }^{29}$ : The score was achieved by summing the percentage score and intensity score providing a score between 0 and 6 . The percentage of Ezrin-positive cells was scored as follows: $0=$ none of tumor cells stained positive; $1+=1 \%$ to $30 \%$ of tumor cells stained positive; $2+=31 \%$ to $75 \%$ of tumor cells stained positive; $3+=$ $76 \%$ to $100 \%$ of tumor cells stained positive. Meanwhile, staining intensity was scored as follows: 1 = weak expression; 2 = moderate expression; 3 = strong or intensity expression. In each case, 10 high-power fields of representative areas were counted. The staining was evaluated independently by two pathologists, and any discrepancy was resolved by consensus review.

\section{Luciferase Reporter Assay}

The putative miR-183 binding site at the 3' UTR of Ezrin was cloned downstream of a firefly luciferase cassette in a pmirGLO Dual-Luciferase miRNA Target Expression Vector (Promega, Madison, WI). One mutant construct was generated by mutations of the first seven complementary seed sequence to the miR-183 binding region. A $2-\mu \mathrm{g}$ quantity of sense and anti-sense oligonucleotides that encompassed the miR-183 recognition site were synthesized (BGI-Shenzhen, Beijing, China) and annealed in $30 \mathrm{mmol} / \mathrm{L}$ Oligo Annealing Buffer (Promega).

The oligonucleotide sequences used were as follows: wild type: sense 5'-CTAGCGGCCGCCAGGACTTCCATCTGTGCCATAG-3' and anti-sense 5' -TCGACTATGGCACAGATGGAAGTCCTGGCGGCCGCTAGAGCT-3'; and mutant type: sense 5'-CTAGCGGCCGCCAGGACTTCCATCTGACGGTATG-3' and anti-sense 5'-TCGACATACCGTCAGATGGAAGTCCTGGCGGCCGCTAGAGCT-3' . The recognition sequences of miR-183 are underlined and the mutations introduced are shown in boldface type.

The annealed oligonucletides were introduced with Sacl and Sall sites, and a nique Notl site was added to test for positive clones. Constructs contained either an exact match to the 22-bp miR-183 target sequence or a mismatched version of that target site were cotransfected into MG63-H and Saos2-H cells with miR-183 or miRcontrol RNA using Lipofectamine 2000 (Invitrogen). Twenty-four hours after transfection, cells were analyzed for luciferase activity using the Dual-Glo Luciferase Assay System (Promega) and a MicroLumatPlus LB96V luminometer (Berthold). Normalized firefly luciferase activity (firefly luciferase activity/Renilla luciferase activity) for each construct was compared with that of the pmirGLO Vector no insert (NO) control. For each transfection, luciferase activity was averaged from three replicates.

\section{Cell Proliferation Assay}

Cells were grown in RPMI-1640 medium supplemented with $10 \%$ FBS. Cells $\left(1 \times 10^{3}\right)$ were seeded in 96-well plates in triplicate and incubated at $37^{\circ} \mathrm{C}$ in $5 \% \mathrm{CO}_{2}$ for 24 hours. The MTT working solution was added to the medium, and the cells were incubated for 4 hours. The medium was removed, and $150 \mu$ l of DMSO was added to dissolve the formazan crystals. Cell viability was assessed daily by absorbance at $490 \mathrm{~nm}$ using a microplate reader (model 680 Microplate Reader, Bio-Rad) for 5 consecutive days. The proliferation assay was performed in triplicate and repeated three times.

\section{Cell Cycle Analysis}

Cells were collected by trypsinization, washed in PBS, and fixed in $70 \%$ ethanol for 30 minutes at $4^{\circ} \mathrm{C}$. After washing with PBS, cells were incubated with the DNAbinding dye propidium iodide $(50 \mu \mathrm{g} / \mathrm{mL})$ and RNase (1.0 $\mathrm{mg} / \mathrm{mL}$ ) for 30 minutes at $37^{\circ} \mathrm{C}$ in the dark. Finally, cells were washed and red fluorescence was analyzed by a FACSCalibur flow cytometer (Becton Dickinson, Franklin Lakes, NJ) with Cell Quest Pro software. Cell cycle analysis was performed in triplicate and repeated three times.

\section{Transwell Cell Invasion and Migration Assay}

For invasion assay, MG63-H/L and Saos2-H/L transfectants were trypsinized and resuspended to a density of $5 \times 10^{5} / \mathrm{mL}$ in serum-free RPMI-1640 medium. A 300- $\mu$ l cell suspension was added to the upper chamber of each well in 24-well polycarbonate transwell membrane inserts (8- $\mu \mathrm{m}$ pore size; BD Biosciences) coated with $30 \mathrm{mg} / \mathrm{cm}^{2}$ of Matrigel. After 24 hours at $37^{\circ} \mathrm{C}$, cells on the upper membrane surface were removed by careful wiping with a cotton swab, and the filters were fixed by treatment with 95\% ethanol for 30 minutes and stained with $0.2 \%$ Crystal Violet solution for 30 minutes. Invasion cells adhering to the undersurface of the filter were then counted (five high-power fields per chamber) using an inverted microscope. The migration assay was performed the same as the invasion assay except that no matrigel was used and the permeating time for cells was 12 hours.

\section{Statistical Analysis}

All data were presented as mean \pm SE and analyzed using Prism 5.0 software (GraphPad, La Jolla, CA). The significance of the observed differences was determined with the Student's $t$-test or one-way analysis of variance. The relationships between miR-183 and Ezrin mRNA or protein were analyzed by correlation coefficients and linear regression analysis. $P<0.05$ was considered statistically significant. 

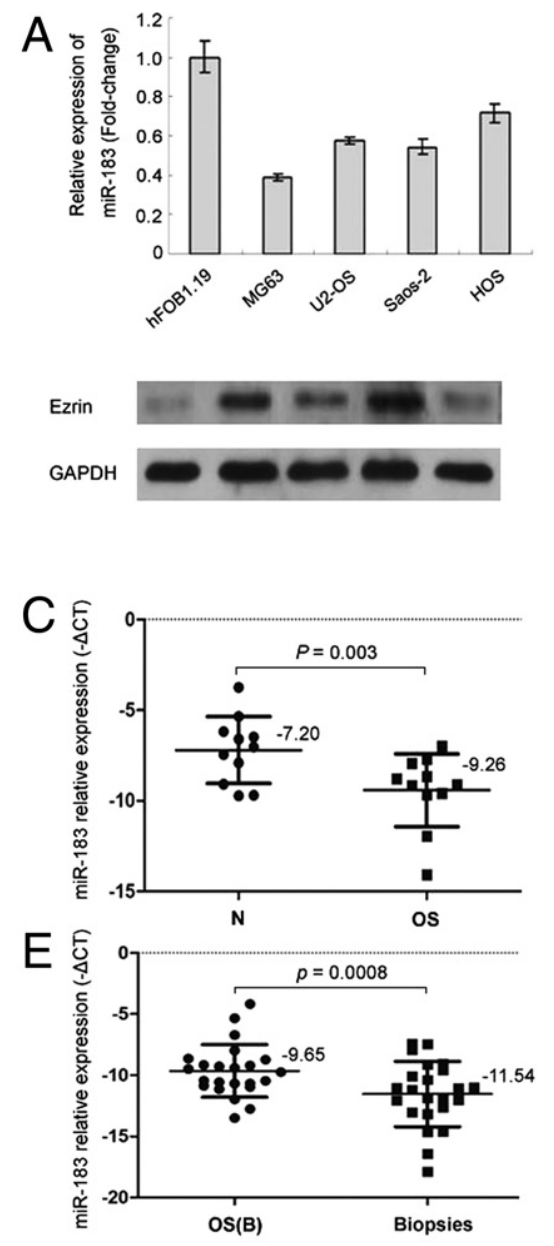

\section{Results}

\section{miR-183 Expression Patterns in Human Osteosarcoma Cells and Tissues}

RT-qPCR analysis showed that miR-183 level was lower in four osteosarcoma cell lines, namely, MG63, U2-OS, Saos-2, and HOS, than in the osteoblastic hFOB1.19 cell line (Figure 1A, top). Comparative analysis indicated that miR-183 was differentially down-regulated in all four examined fresh samples compared with matched nontumoral bone tissues from the same patients (Figure 1B).

To determine the potential clinicopathological implications of altered miR-183 expression, we examined the expression of miR-183 in 27 cases of paraffin-embedded, archived, surgical resection primary osteosarcoma (among which 10 had paired nontumoral bone tissues, nine had paired lung metastases, seven had paired local recurrences, and one had both paired nontumoral bone tissues and lung metastases) by quantitative RT-PCR. Consistent with of the results on cell lines and fresh samples, miR-183 level was significantly down-regulated in 11 cases of primary osteosarcoma (OS) $(-9.26 \pm 0.36)$ compared with paired nontumoral bone tissues $(\mathrm{N})$ $(-7.20 \pm 0.56)(P=0.003, \mathrm{t}=-3.885$, paired $t$-test $)$ (Figure 1C). The correlation between miR-183 expression level and clinicopathologic characteristics of osteosar- coma is summarized in Table 1. The expression level of miR-183 was $-10.73 \pm 0.43$ in 17 cases at advanced stages (with lung metastases or local recurrences), but was $-9.43 \pm 0.34$ in 10 cases at early stages (primary disease) $(P=0.048, \mathrm{t}=2.077$, unpaired $t$-test). The expression level of miR-183 was not correlated with age, sex, tumor site, histological subtypes, or surgical method. In addition, the expression level of miR-183 was significantly lower in lung metastases $(-12.70 \pm 1.10)$ compared with paired primary osteosarcoma OS (L) $(-10.53 \pm 0.61)(P=0.028, \mathrm{t}=2.622$, paired $t$-test $)$ (Figure 1D). Furthermore, decreased expression of miR183 was observed in local recurrences $(-12.53 \pm 0.96)$ compared with paired primary osteosarcoma OS (R) $(-11.01 \pm 0.61)(P=0.036, \mathrm{t}=2.698$, paired $t$-test $)$ (Figure 1D).

To investigate whether chemotherapy would affect the miR-183 expression level, we compared 23 cases of primary osteosarcoma at tumor resection after preoperative chemotherapy with biopsy tissues before neoadjuvant chemotherapy obtained from the same patient. The clinical characteristics of patients were shown in Table 2. Quantitative RT-PCR assay showed that the expression level of miR-183 in biopsy samples $(-11.54 \pm 0.56)$ was markedly decreased compared with paired primary osteosarcoma OS (B) $(-9.65 \pm 0.45)(P=$ 
A

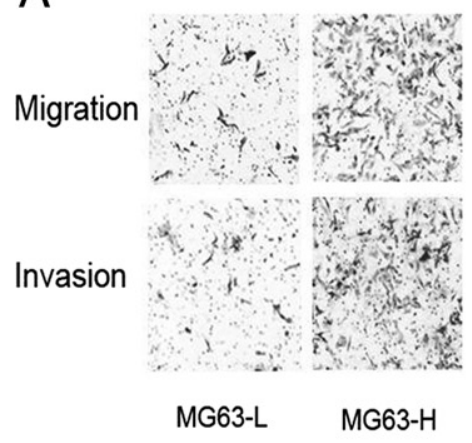

B

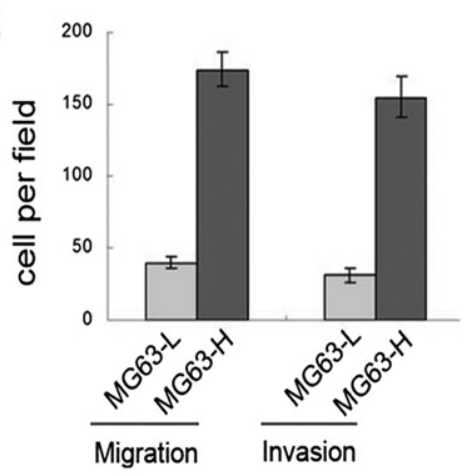

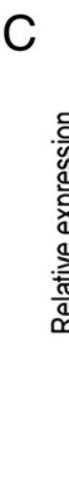

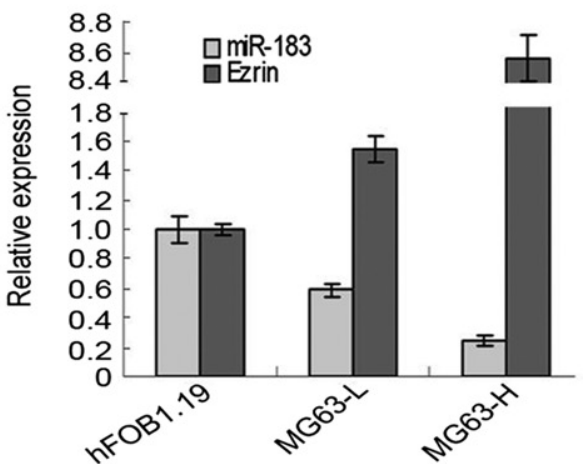

Figure 2. The metastatic characteristics of cell sublines. A: In vitro migration and invasion ability of each cell subline. Magnification, $\times 100$. B: Bar graphs representing the average number of cells on the underside of membranes. C: RT-qPCR analysis indicated that relative expression of miR-183 and Ezrin were reversed in high-invasive (MG63-H) and low-invasive (MG63-L) cells compared with osteoblastic hFOB1.19 cells. Error bars (SD) were calculated from triplicate samples.

0.0008, $t=3.891$, paired $t$-test) (Figure 1E). Downregulation of miR-183 was observed in $74 \%$ (17/23) of biopsy samples compared with their paired osteosarcoma with preoperative chemotherapy, suggesting that chemotherapy could upregulate the expression of miR-183 in osteosarcoma.

\section{Ectopic Expression of miR-183 Inhibits Osteosarcoma Cell Migration and Invasion in Vitro}

To explore the role of miR-183 in osteosarcoma metastasis, we created high-invasion (MG63-H and Saos2-H) and low-invasion (MG63-L and Saos2-L) cell sublines from the human osteosarcoma cell lines MG63 and Saos2 by using the repeated transwell approach. With the same genetic background, the two paired selected cell sublines were similar except for the metastatic abilities. The migration ability of MG63-H cells was about fourfold higher than that of MG63-L cells. Likewise, the invasion ability of MG63-H cells was about fivefold higher than that of MG63-L cells (Figure 2, A and B). Notably, the miR-183 expression level was significantly lower in MG63-H cells than in MG63-L cells (Figure 2C). Similar results were observed in Saos2 cell lines (see Supplemental Figure S1 at http://ajp.amjpathol.org).

Next we examined the migration and invasion of MG63-H/L and Saos2-H/L cells on gain or loss of miR183. We found that ectopic expression of miR-183 resulted in an approximately threefold reduction in migration and invasion of MG63-H cells, which had low level of endogenous miR-183 (Figure 3A). Consistently, the loss of miR-183 led to a four- to fivefold increase in the migration and invasion of MG63-L cells (Figure 3, B and C). Similar results were observed in Saos2 cell lines (see Supplemental Figure S2 at http://ajp.amjpathol.org).

To confirm the role of miR-183 in the regulation of tumor invasion, we excluded the effect of miR-183 on the proliferation and cell cycle distribution of osteosarcoma cells. Overexpression of miR-183 did not affect the proliferation and the cell cycle distribution of MG63-H (Figure 4, A and B) and Saos2-H (see Supplemental Figure S3, A and B at http://ajp.amjpathol.org) cells in vitro. These results indicate that miR-183 has the ability to suppress metastasis without affecting cell proliferation or cell cycle distribution.

\section{Inverse Correlation of miR-183 and Ezrin Expression in Osteosarcoma Cells and Tissues}

To elucidate the mechanism by which miR-183 inhibits the migration and invasion of osteosarcoma, we performed in silico analysis using three miRNA target prediction programs, namely, TargerScan, PicTar, and miRanda. On the basis of miRNA target prediction, Ezrin was the only target gene harboring the binding site of miR-183 in the 3'UTR predicted by all three programs. Thus we hypothesized that Ezrin may be involved in the inhibitory effects of miR-183 on the migration and invasion of osteosarcoma. Analysis of the expression of miR183 and Ezrin in hFOB1.19 and in MG63-H/L and Saos2$\mathrm{H} / \mathrm{L}$ cells showed a negative correlation between miR-183 and Ezrin mRNA levels in these cells (Figure 2C; see also Supplemental Figure S1C at $h$ ttp://ajp.amjpathol.org). Furthermore, Ezrin mRNA and protein levels were decreased when miR-183 mimics were transfected into MG63-H (Figure 5, A and C) and Saos2-H cells (see Supplemental Figure S4, A and C at http://ajp.amjpathol.org), and were increased when miR-183 was knocked down by miR-183 inhibitor in MG63-L (Figure 5, B and C) and Saos2- L cells (see Supplemental Figure S4, B and C at http://ajp. amjpathol.org). These results suggest that reduced miR183 expression is likely responsible for increased Ezrin expression in osteosarcoma cells. To test whether these findings could be recapitulated in primary osteosarcoma, we examined Ezrin and miR-183 expression in four sets of osteosarcoma and paired normal bone tissue specimens. We found that in osteosarcoma where miR-183 level was low (Figure 1B, bottom), Ezrin mRNA was elevated compared with corresponding normal tissues (Figure 1B, top). Taken together, these results suggest that Ezrin is negatively regulated by miR-183 in osteosarcoma cell lines and a subset of primary osteosarcoma tumors. 

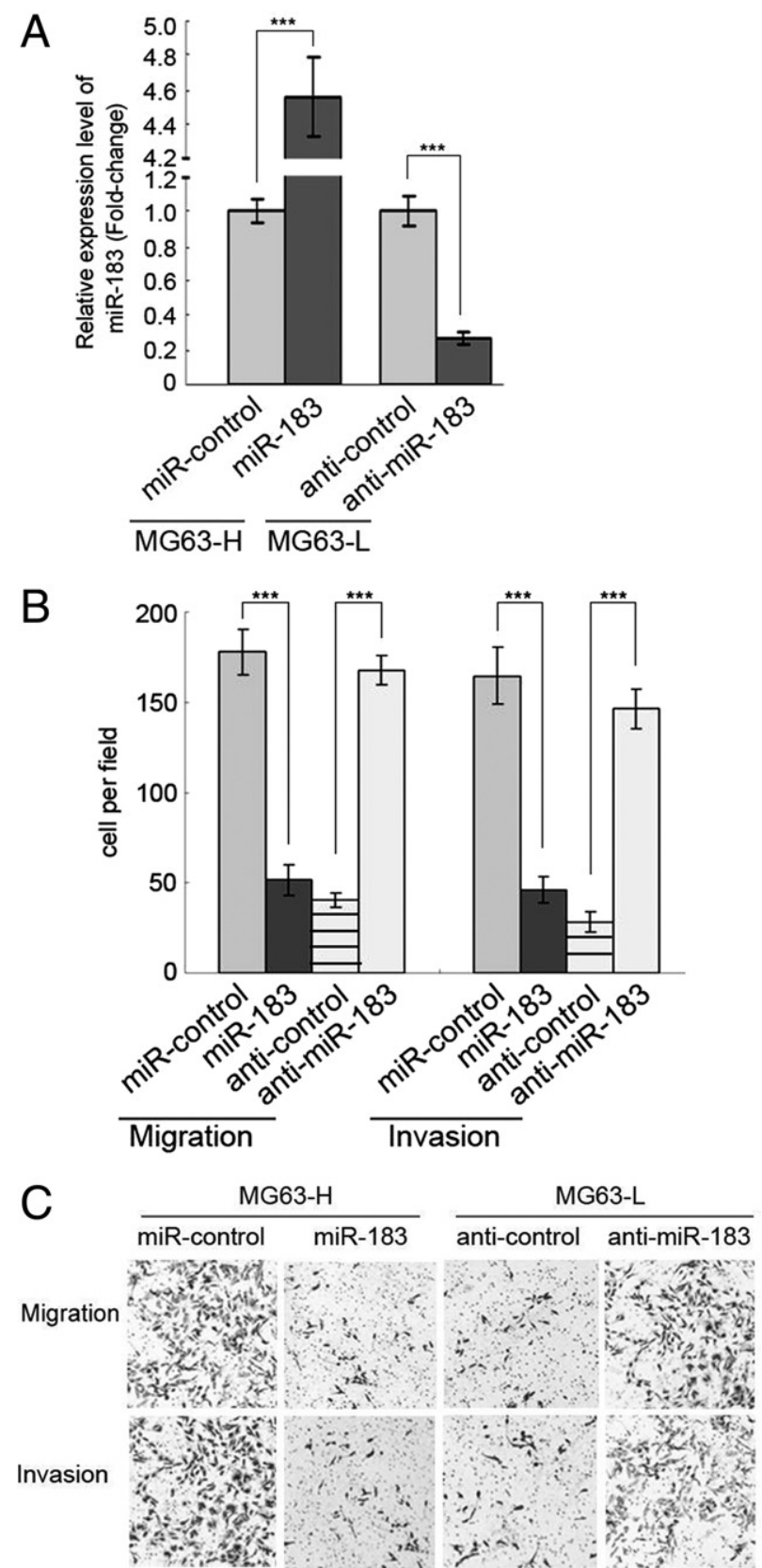

Figure 3. miR-183 suppresses osteosarcoma cell invasion and migration. A: RT-qPCR analysis of miR-183 in MG63-H cells transfected with miR-control or miR-183 and MG63-L cells transfected with anti-control or anti-miR-183. B: Average numbers of migratory and invasive cells from three independent experiments are shown. C: Representative images of migratory and invasive cells on polycarbonate transwell membrane. ${ }^{* * * *} P=0.000$.

The inverse relationship between miR-183 and Ezrin expression levels was further confirmed by quantitative RT-PCR and immunohistochemistry analysis in 50 cases of primary osteosarcoma, 11 matched adjacent nontumoral bone tissues, and 17 matched lung metastases and local recurrences. As expected, the mRNA expression levels of Ezrin were negatively correlated with miR183 levels (Figure 5D). In our series, immunohistochemical analysis indicated that Ezrin was abundant in osteosarcomas, especially in advanced stages (lung me- tastases and local recurrences) compared with primary tumors (Figure 5F), in which miR-183 expression was low. Correlative analysis of Ezrin protein score with miR-183 expression suggested an inverse relationship (Figure $5 \mathrm{E})$. These results suggest that down-regulation of miR183 may account for Ezrin upregulation in human osteosarcoma. However, we observed that miR-183 dysregulation in some osteosarcomas could not account for the high expression level of Ezrin, indicating that miR-183 might play a critical role in the regulation of Ezrin in most but not all of the osteosarcoma. We speculate that other factors might antagonize or interfere with the effect of miR-183 on Ezrin expression and may warrant further investigation.

\section{Ezrin Is a Direct Target Gene of miR-183 in Osteosarcoma Cells}

To obtain further direct evidence that Ezrin is a target of miR-183, we characterized the binding site of miR-183 in the $3^{\prime}$ UTR of Ezrin mRNA. The results showed that miR183 but not miR-control RNA specifically decreased the luciferase activity (Figure 6A). The mutant reporter cotransfected with miR-183 did not show significant decrease in the relative luciferase activity compared with negative control RNA.

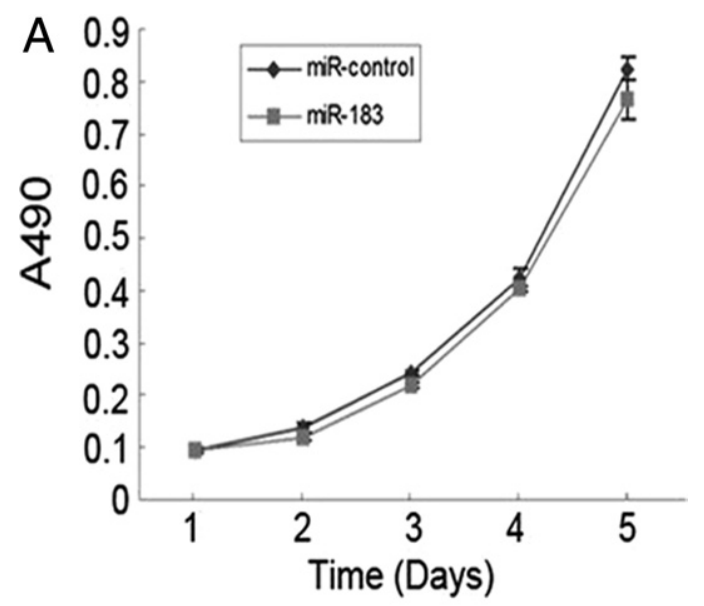

B

\begin{tabular}{lllll}
\hline & G1 & G2 & \multicolumn{1}{c}{$S$} & G2 G1 \\
\hline miR-control & 70.333 & 7.267 & 22.4 & 1.911 \\
& \pm 3.15 & \pm 1.36 & \pm 2.87 & \pm 0.02 \\
miR-183 & 69.233 & 8.3 & 22.467 & 1.874 \\
& \pm 3.93 & \pm 0.8 & \pm 3.13 & \pm 0.02 \\
\hline \multicolumn{5}{c}{ Cell cycle distribution }
\end{tabular}

Figure 4. Proliferation rate and cell cycle of each cell subline. A: Proliferation rates of the cell sublines were detected by MTT assay. B: Cell cycle distribution $(P>0.05 ; n=3)$ was detected by flow cytometry anlysis. 

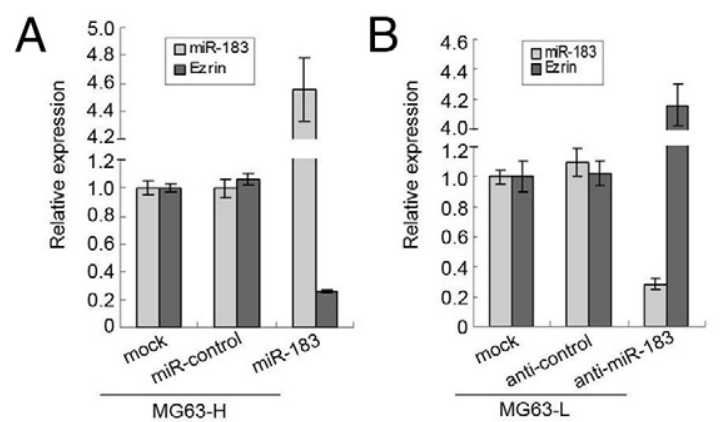

C
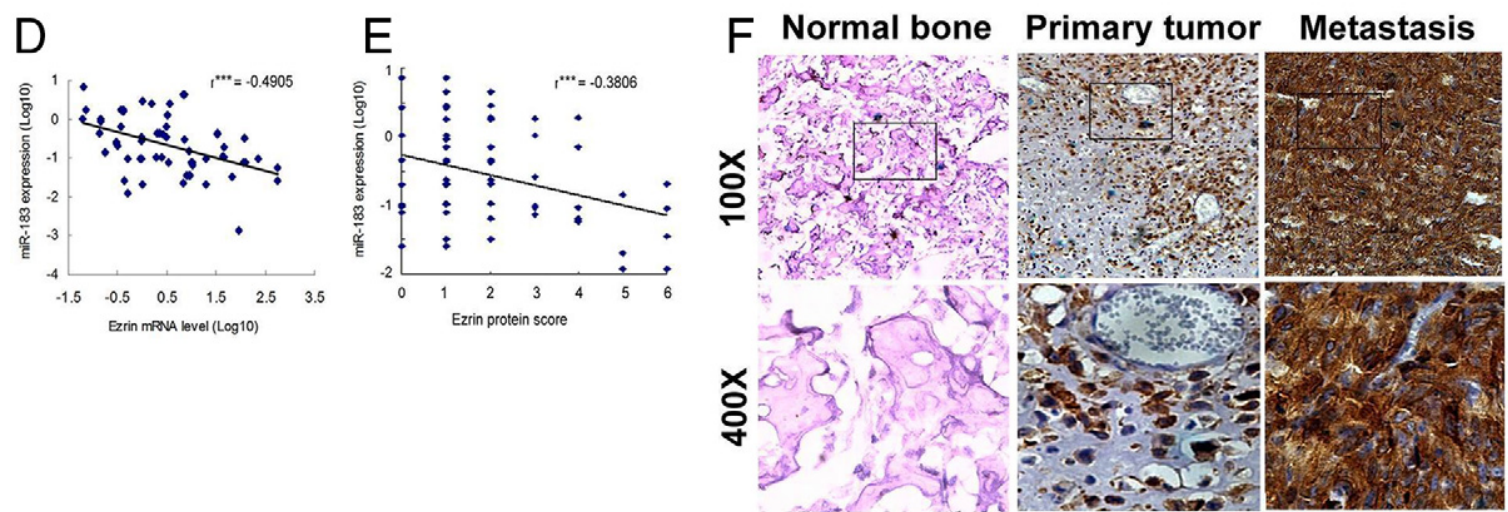

Figure 5. Inverse correlation of miR-183 levels with mRNA and protein levels of Ezrin in osteosarcoma cell lines and osteosarcoma tissues. Ezrin mRNA (A) and protein (C) levels decreased when miR-183 was up-regulated in MG63-H cells, but Ezrin mRNA (B) and protein (C) levels increased when miR-183 was down-regulated in MG63-L cells. $\beta$-Actin was used as a loading control. D: An inverse relationship between miR-183 expressions with Ezrin mRNA level is suggested. $\mathrm{r}^{\text {******}}=-0.4767$ with a significant $P$ value $=0.000 . \mathbf{E}$ : An inverse relationship between miR-183 expressions with Ezrin protein level was suggested. $\mathrm{r}^{* *}=$ -0.3639 with a significant $P=0.037$. F: Representative immunostaining of Ezrin in normal bone tissue, primary osteosarcoma, and the lung metastases from the same patient. Ezrin expression was low or undetected in normal bone tissues and was high in primary osteosarcoma, especially in metastases. Original magnification $\times 100$ (top); $\times 400$ (bottom, magnified box from top panels).

Ezrin is known to promote tumor angiogenesis and metastasis of various solid tumors such as osteosarcoma. To determine whether miRNA-183 reduces the migration of MG63-H cells in Ezrin-dependent manner,

\section{A}

Position 367-373 of EZR 3' UTR 5' . . GCAGGACUUCCAUCUGUGCCAUA... hsa-miR-183 3 . UCACUUAB 1111111

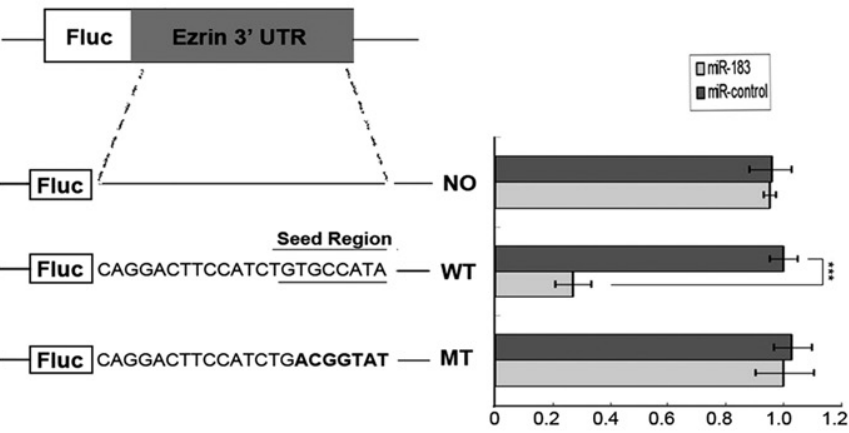

Relative Luciferase activity we used an expression construct that encoded the entire Ezrin coding sequence but lacked the $3^{\prime}$ UTR, yielding an mRNA resistant to miRNA-mediated suppression. Our results showed that overexpression of

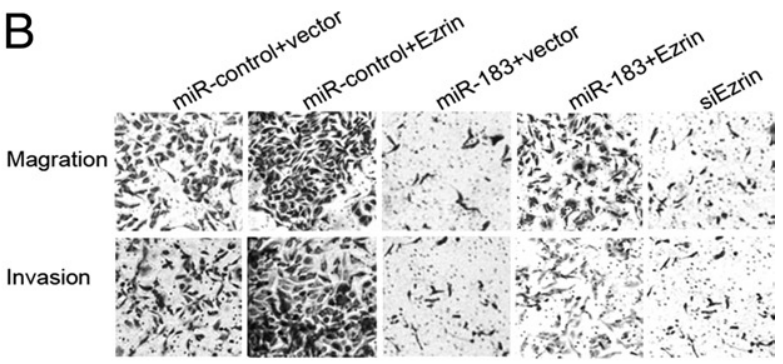

C

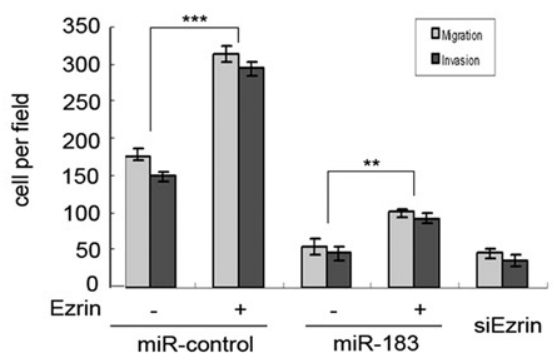

Figure 6. miR-183 inhibits osteosarcoma cell migration and invasion in vitro by suppressing Ezrin expression. A: Base pairing complement suggested that Ezrin $3^{\prime}$ UTR was a potential target of miR-183. The no-insert control (NO), wild-type (WT), and mutated-type (MT) constructs were shown with the seed region underlined and base substitutions in bold. The firefly luciferase activity was standardized to renilla luciferase control. Results from three independent experiments are shown. B: Representative images of migratory and invasive cells on membrane of miR-control or miR-183 transfected MG63-H cells with or without ectopic expression of Ezrin. C: Average numbers of migratory and invasive cells from three independent experiments are shown. ${ }^{* *} P<0.01 ;{ }^{* * * *} P<0.001$. 

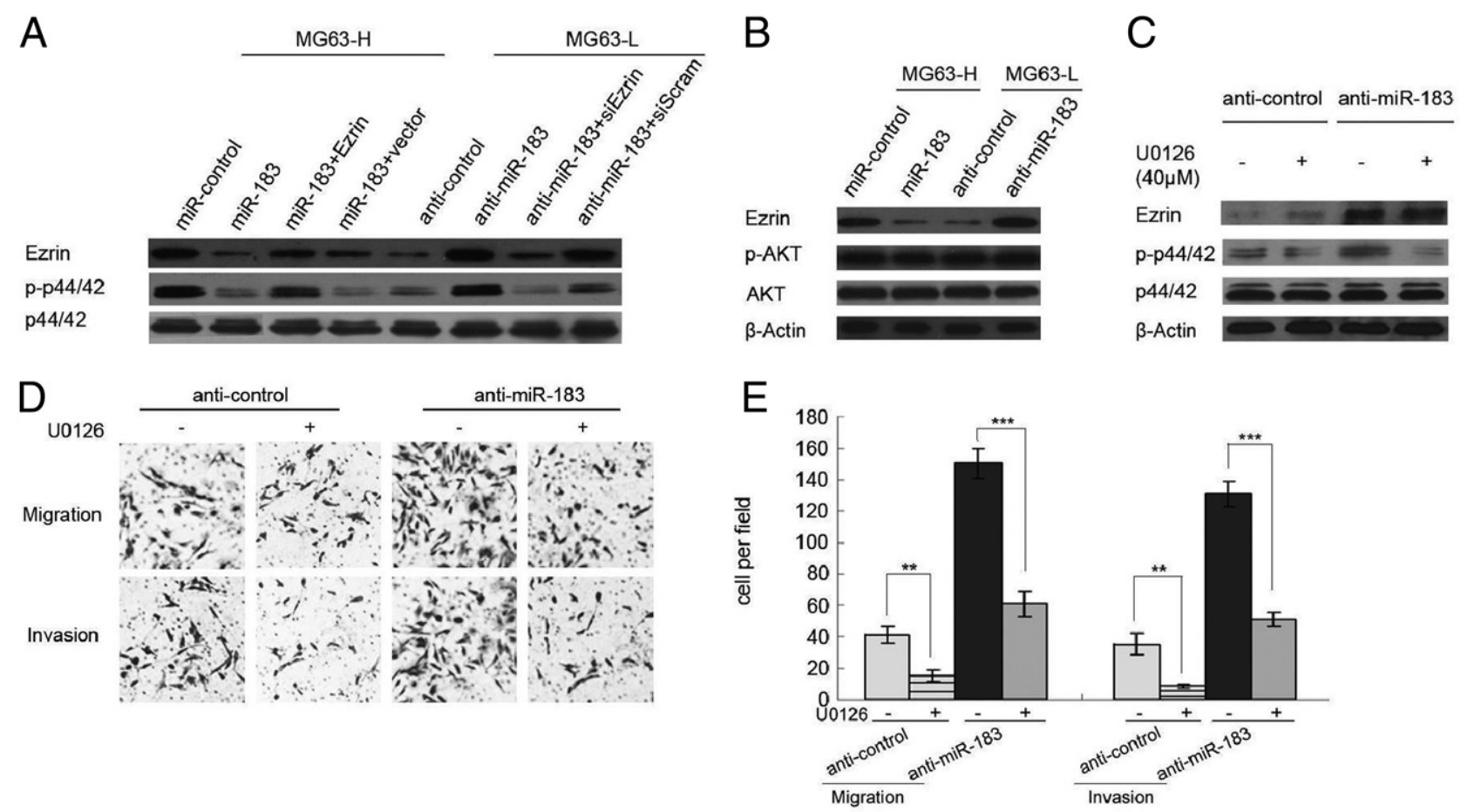

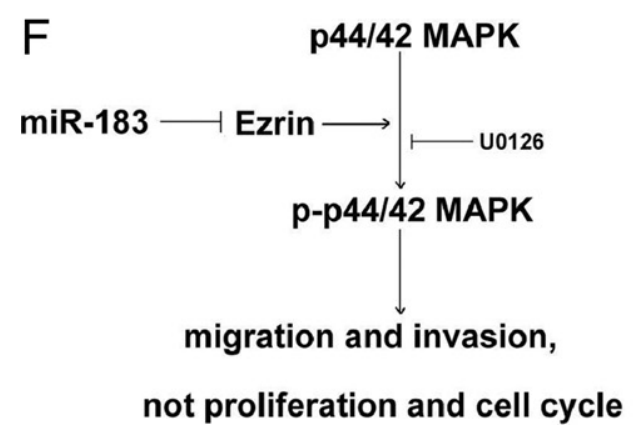

Figure 7. miR-183 inhibits osteosarcoma cell migration and invasion in vitro by inhibiting the activation of p44/42 MAPK signaling. A: Western blots of Ezrin and p44/42-MAPK phosphorylation in MG63-H cells transfected with miR-183 in the presence of Ezrin or vector control and in MG63-L cells transfected with anti-miR-183 in the presence of siEzrin or scram control. B: The levels of Ezrin, phosphorylated-AKT, and total AKT were determined by Western blot of MG63-H transfected with miR-control or miR-183 and of MG63-L cells transfected with anti-control or anti-miR-183. C and D: MEK1/2 inhibitor U0126 abrogated the effects of anti-miR-183 on p44/42 activation and cell migration and invasion. Western blot (C) and representative images of migratory and invasive cells on membrane (D) of MG63-L cells transfected with anti-miR-control or anti-miR-183. A 10- $\mu \mathrm{mol} / \mathrm{L}$ quantity of U0126 was added 2 hours before RNA transfection. Cells were harvested at 72 hours for Western blot and 48 hours for transwell assay. E: Average numbers of migratory and invasive cells from three independent experiments were shown. ${ }^{*} P<0.01$; ${ }_{\text {*al }} P<0.001$. F: Schematic model of the role of miR-183 in osteosarcoma migration and invasion. As a tumor suppressor, miR-183 inhibits osteosarcoma migration and invasion via posttranscriptional silencing of Ezrin expression and consequently inhibiting p44/42 MAPK activation. Eventually, cell migration and invasion are inhibited without affecting cell proliferation and cell cycle distribution.
Ezrin protein with pcDNA-Ezrin greatly enhanced the migration and invasion of MG63-H cells (Figure 6, B and $\mathrm{C}$ ). As expected, cotransfection of pcDNA-Ezrin and miR-183 mimics into MG63-H (Figure 6, B and C) cells significantly rescued miR-183 suppressed migration and invasion. The restoration of Ezrin expression partly attenuated the anti-metastatic function of miR183 in osteosarcoma cells, further suggesting that Ezrin down-regulation is necessary but not sufficient to mediate the anti-metastatic effects of miR-183 in osteosarcoma. Ezrin is therefore a critical target of miR183, but other functionally important miR-183 targets remain to be identified. In addition, knockdown of Ezrin by siRNA in MG63-H (Figure 6, B and C) inhibited cell invasion to the levels similar to those observed after transfection with miR-183 mimics. And similar results were observed in Saos2-H cells (see Supplemental Figure S5, A and B at http://ajp.amjpathol.org). These results indicate that a reduction of Ezrin expression can mimic miR-183 in suppressing the migratory and invasive ability of osteosarcoma cells. Taken together, these data indicate that the down-regulation of Ezrin by miR-183 is the mechanism by which miR-183 induces decreased metastasis in osteosarcoma.

\section{miR-183 Silencing Enhances p44/42 MAPK Signaling via the Upregulation of Ezrin in Osteosarcoma Cells}

MAPK pathway is crucially involved in cancer metastases. ${ }^{30,31}$ However, a previous study showed that Ezrin mediated the growth and survival in Ewing's sarcoma through the AKT/mTOR but not the MAPK signaling. ${ }^{32}$ Therefore, we determined whether miR-183 mediated Ezrin suppression would affect AKT/mTOR or p44/42 MAPK signaling. Our results showed that miR-183 overexpression in MG63-H and Saos2-H cells reduced the level of phosphorylated-p44/42 protein without altering the total p44/42 level, and this reduction could be eliminated by Ezrin overexpression. On the other hand, the down-regulation of miR-183 expression in MG63-L and Saos2-L cells increased the level of phosphorylated-p44/42 protein, and this increase could be eliminated by Ezrin siRNA (Figure 7A; see also Supplemental Figure S6A at http://ajp.amjpathol.org). Moreover, we observed no obvious changes in the protein levels of Akt and phosphorylated-Akt in both the miR-183-silenced MG63-L or Saos2-L cells and miR-183 overexpressed MG63-H or 
Saos2-H cells (Figure 7B; see also Supplemental Figure S6B at http://ajp.amjpathol.org). Furthermore, we used U0126, a highly selective and potent inhibitor of p44/42, to validate the regulatory role of miR-183-Ezrin-p44/42 axis in osteosarcoma metastasis. Our results showed that anti-miR-183 activated p-p44/42 in MG63-L (Figure 7C) and Saos2-L (see Supplemental Figure S6C at $h t t p: / / a j p$. amjpathol.org) cells and U0126 abrogated the activation of $p-p 44 / 42$ and the increased migration and invasion in these cells (Figure 7, D and E; see also Supplemental Figure S6, D and E, at http://ajp.amjpathol.org). Collectively, these results demonstrate that miR-183 silencing enhances p44/42 MAPK signaling via the upregulation of Ezrin in osteosarcoma cells. Thus we propose that miR183 may function to inhibit osteosarcoma metastasis by suppressing MAPK/p44/42 signaling.

\section{Discussion}

The key finding of the current study is that miR-183 is down-regulated in osteosarcoma and its down-regulation is associated with the progression of osteosarcoma. We found that miR-183 expression is down-regulated in osteosarcoma cells and tissues compared with osteoblastic cells and paired adjacent nontumoral bone tissues, respectively, and miR-183 expression level was much less in lung metastases and local recurrences than paired primary osteosarcoma. Statistical analyses reveal that the expression level of miR-183 was significantly correlated with the lung metastasis and recurrence of the osteosarcoma. In addition, we found that miR-183-mediated suppression of cell migration and invasion is due to the silencing of Ezrin and is associated with down-regulation of $p-p 44 / 42$. Furthermore, significantly higher miR-183 level was found in surgical resected primary osteosarcoma than matched biopsy without chemotherapy. Taken together, these data suggest that miR-183 is a promising prognostic marker and therapeutic target for osteosarcoma metastasis.

The molecular pathways involved in osteosarcoma carcinogenesis have been well studied. ${ }^{33,34}$ However, few studies have used matching control groups or representative cases, and no single genetic alteration has been used to divide patients into high risk or low risk of recurrence or metastases routinely. To overcome these limitations, we designed a paired analysis in which samples of primary osteosarcoma were compared with samples of normal bone tissue or lung metastasis or local recurrence or biopsy from the same patient.

Archived FFPE specimens represent excellent resources for biomarker discovery. Li et $\mathrm{al}^{35}$ showed that the expression profiles of miRNAs were in good correlation between fresh frozen and FFPE samples, and formalin fixation did not change the stability of miRNAs based on real-time RT-qPCR analysis. In addition, they found no significant differences of representative miRNA expression among 40 colorectal cancer FFPE specimens. Xi et $\mathrm{al}^{36}$ found that miRNAs demonstrated reliable expression levels in FFPE compared with snap-frozen paired samples. Glud et al ${ }^{37}$ also showed a high correlation in
miRNA expression between paired FFPE and fresh-frozen material. All of these data provide a foundation for miRNA investigation using FFPE samples in cancer and other types of diseases. One of the limitations for basic research in osteosarcoma is that most tissues are decalcified before histological analyses, resulting in the degradation of nucleic acids. Our study demonstrates successful use of FFPE tissues for quantitative miRNA analysis. This is particularly important in osteosarcoma tumor, in which the availability of fresh tissue without chemoradiation is very limited because most patients, at least in our institution, who undergo surgical resection have had prior chemoradiation therapy.

In our study, we found lower levels of miR-183 in osteosarcoma compared with matching nontumoral bone tissue and the expression level of miR-183 was significantly negatively correlated with the lung metastasis and recurrence of the osteosarcoma. Our finding is consistent with recent reports showing that down-regulation of miR183 promoted metastasis in breast ${ }^{38}$ and lung ${ }^{23}$ cancers. These results collectively suggest that miR-183 functions as tumor suppressor. Further prospective studies are required to confirm the prognostic value of miR-183 in a large cohort of osteosarcoma patients to promote its application in clinical practice.

Ezrin is known to play an important role in the metastasis of various human cancers. ${ }^{38-41}$ Silico analysis indicated that Ezrin was a predicted target of miR-183 based on three prediction programs, namely, miRBase, TargetScan, and PicTar. ${ }^{42-44}$ Wang et al recently reported that miR-183 down-regulated the expression of Ezrin and inhibited lung cancer metastasis. ${ }^{23}$ Folio et al ${ }^{45}$ provided evidence that Ezrin was one of 16 identified proteins involved in bone pathogenesis in a paired analysis study of osteosarcomas. In our study, we found that Ezrin was expressed at high levels in high-invasive cells and at low levels in low-invasive cells, whereas miR-183 displayed the opposite expression pattern. It is likely that the downregulation of Ezrin by miR-183 contributed to the tumor suppression function of miR-183 in osteosarcoma. Furthermore, we found that the overexpression of miR-183 could indirectly down-regulate MAPK/ERK signaling by suppressing Ezrin, resulting in the inhibition of cancer cell invasion and metastasis. Although it has been reported that Ezrin could regulate AKT signaling, ${ }^{41}$ we did not find significant changes in the activation of AKT pathway in osteosarcoma cells on the gain or loss of miR-183 or Ezrin, which is consistent with previous study on pancreatic cancer cells. ${ }^{46}$ Taken together, we propose that miR183 inhibits the invasion and metastasis of osteosarcoma mainly through the down-regulation of Ezrin and MAPK/ ERK signaling.

The neoadjuvant chemotherapy has dramatically improved the long-term disease-free survival and the cure rate of patients with osteosarcoma from $10 \%$ to $15 \%$ up to $50 \%$ to $70 \%{ }^{47,48}$ Previous studies reported that the patients who responded favorably to neoadjuvant chemotherapy with $90 \%$ or greater necrosis had a $70 \%$ to $87 \%$ 5 -year overall survival, whereas the patients with a poor response of less than 90\% necrosis had less than a 50\% 5-year overall survival. ${ }^{5,49,50}$ In the present study, we 
found that increased expression level of miR-183 was observed in primary osteosarcoma after neoadjuvant chemotherapy compared with that in paired biopsy without neoadjuvant chemotherapy. It is likely that chemotherapy could upregulate the expression level of miR-183 in osteosarcoma, which could boost the sensitivity to preoperative chemotherapy in osteosarcoma patients. However, further studies are necessary to elucidate the underlying mechanisms.

\section{Conclusion}

In conclusion, this study demonstrates that miR-183 functions as a tumor suppressor miRNA in osteosarcoma by suppressing Ezrin expression and inhibiting MAPK/ERK activation (Figure 7F). Importantly, the miR-183-EzrinMAPK/ERK axis that we identified may be exploited for therapeutic intervention to inhibit osteosarcoma progression and metastasis.

\section{Acknowledgments}

We thank Wenhui Zhang and Canqiao Luo for collection and preparing formalin-fixed, paraffin-embedded tissues and Shuhua Li and Jiayan Lian for RT-qPCR assistance.

\section{References}

1. Link MP, Goorin AM, Miser AW, Green AA, Pratt CB, Belasco JB, Pritchard J, Malpas JS, Baker AR, Kirkpatrick JA, et al: The effect of adjuvant chemotherapy on relapse-free survival in patients with osteosarcoma of the extremity. N Engl J Med 1986, 314:1600-1606

2. Meyers PA, Heller G, Healey J, Huvos A, Lane J, Marcove R, Applewhite A, Vlamis V, Rosen G: Chemotherapy for nonmetastatic osteogenic sarcoma: the Memorial Sloan-Kettering experience. J Clin Oncol 1992, 10:5-15

3. Meyers PA, Gorlick R: Osteosarcoma. Pediatr Clin North Am 1997, 44:973-989

4. Bacci G, Mercuri M, Briccoli A, Ferrari S, Bertoni F, Donati D, Monti C, Zanoni A, Forni C, Manfrini M: Osteogenic sarcoma of the extremity with detectable lung metastases at presentation. Results of treatment of 23 patients with chemotherapy followed by simultaneous resection of primary and metastatic lesions. Cancer 1997, 79:245-254

5. Bacci G, Longhi A, Versari M, Mercuri M, Briccoli A, Picci P: Prognostic factors for osteosarcoma of the extremity treated with neoadjuvant chemotherapy: 15-year experience in 789 patients treated at a single institution. Cancer 2006, 106:1154-1161

6. Visone R, Croce CM: miRNAs and cancer. Am J Pathol 2009, 174: 1131-1138

7. Calin GA, Croce CM: MicroRNA signatures in human cancers. Nat Rev Cancer 2006, 6:857-866

8. Nicoloso MS, Spizzo R, Shimizu M, Rossi S, Calin GA: MicroRNAsthe micro steering wheel of tumour metastases. Nat Rev Cancer 2009 9:293-302

9. Ma L, Young J, Prabhala H, Pan E, Mestdagh P, Muth D, TeruyaFeldstein J, Reinhardt F, Onder TT, Valastyan S, Westermann F, Speleman F, Vandesompele J, Weinberg RA: miR-9, a MYC/MYCNactivated microRNA, regulates E-cadherin and cancer metastasis. Nat Cell Biol 2010, 12:247-256

10. Ma L, Teruya-Feldstein J, Weinberg RA: Tumour invasion and metastasis initiated by microRNA-10b in breast cancer. Nature 2007, 449: 682-688

11. Sachdeva M, Mo YY: MicroRNA-145 suppresses cell invasion and metastasis by directly targeting mucin 1. Cancer Res 2010, 70:378387

12. Li XF, Yan PJ, Shao ZM: Downregulation of miR-193b contributes to enhance urokinase-type plasminogen activator (UPA) expression and tumor progression and invasion in human breast cancer. Oncogene 2009, 28:3937-3948

13. Wu H, Zhu S, Mo YY: Suppression of cell growth and invasion by miR-205 in breast cancer. Cell Res 2009, 19:439-448

14. Roybal JD, Zang Y, Ahn YH, Yang Y, Gibbons DL, Baird BN, Alvarez C, Thilaganathan N, Liu DD, Saintigny P, Heymach JV, Creighton CJ, Kurie JM: miR-200 Inhibits lung adenocarcinoma cell invasion and metastasis by targeting Flt1/NEGFR1. Mol Cancer Res 2011, 9:25-35

15. Li Y, Vandenboom TG, 2nd, Wang Z, Kong D, Ali S, Philip PA, Sarkar $\mathrm{FH}$ : miR-146a suppresses invasion of pancreatic cancer cells. Cancer Res 2010, 70:1486-1495

16. Kong D, Li Y, Wang Z, Banerjee S, Ahmad A, Kim HR, Sarkar FH: miR-200 regulates PDGF-D-mediated epithelial-mesenchymal transition, adhesion, and invasion of prostate cancer cells. Stem Cells 2009, 27:1712-1721

17. Tie J, Pan Y, Zhao L, Wu K, Liu J, Sun S, Guo X, Wang B, Gang Y, Zhang Y, Li Q, Qiao T, Zhao Q, Nie Y, Fan D: miR-218 inhibits invasion and metastasis of gastric cancer by targeting the Robo1 receptor. PLoS Genet 2010, 6:e1000879

18. Shu M, Zheng X, Wu S, Lu H, Leng T, Zhu W, Zhou Y, Ou Y, Lin X, Lin $Y, X u D$, Zhou Y, Yan G: Targeting oncogenic miR-335 inhibits growth and invasion of malignant astrocytoma cells. Mol Cancer 2011, 10:59

19. Asangani IA, Rasheed SA, Nikolova DA, Leupold JH, Colburn $\mathrm{NH}$, Post S, Allgayer $\mathrm{H}$ : MicroRNA-21 (miR-21) post-transcriptionally downregulates tumor suppressor Pdcd4 and stimulates invasion, intravasation and metastasis in colorectal cancer. Oncogene 2008, 27:2128-2136

20. Osaki M, Takeshita F, Sugimoto Y, Kosaka N, Yamamoto Y, Yoshioka Y, Kobayashi E, Yamada T, Kawai A, Inoue T, Ito H, Oshimura M, Ochiya T: MicroRNA-143 regulates human osteosarcoma metastasis by regulating matrix metalloprotease-13 expression. Mol Ther 2011, 19:1123-1130

21. Yantiss RK, Goodarzi M, Zhou XK, Rennert H, Pirog EC, Banner BF, Chen YT: Clinical, pathologic, and molecular features of early-onset colorectal carcinoma. Am J Surg Pathol 2009, 33:572-582

22. Sarver AL, Li L, Subramanian S: MicroRNA miR-183 functions as an oncogene by targeting the transcription factor EGR1 and promoting tumor cell migration. Cancer Res 2010, 70:9570-9580

23. Wang G, Mao W, Zheng S: MicroRNA-183 regulates Ezrin expression in lung cancer cells. FEBS Lett 2008, 582:3663-3668

24. Lowery AJ, Miller N, Dwyer RM, Kerin MJ: Dysregulated miR-183 inhibits migration in breast cancer cells. BMC Cancer 2010, 10:502

25. Li G, Luna C, Qiu J, Epstein DL, Gonzalez P: Targeting of integrin beta1 and kinesin 2alpha by microRNA 183. J Biol Chem 2010, 285:5461-5471

26. Li J, Fu H, Xu C, Tie Y, Xing R, Zhu J, Qin Y, Sun Z, Zheng X: miR-183 inhibits TGF-beta1-induced apoptosis by downregulation of PDCD4 expression in human hepatocellular carcinoma cells. BMC Cancer 2010, 10:354

27. Chu YW, Yang PC, Yang SC, Shyu YC, Hendrix MJ, Wu R, Wu CW: Selection of invasive and metastatic subpopulations from a human lung adenocarcinoma cell line. Am J Respir Cell Mol Biol 1997, 17:353-360

28. Wang CC, Tsai MF, Dai TH, Hong TM, Chan WK, Chen JJ, Yang PC: Synergistic activation of the tumor suppressor. HLJ1, by the transcription factors YY1 and activator protein 1. Cancer Res 2007, 67:4816-4826

29. Kim MS, Song WS, Cho WH, Lee SY, Jeon DG: Ezrin expression predicts survival in stage IIB osteosarcomas. Clin Orthop Relat Res 2007, 459:229-236

30. Barros JC, Marshall CJ: Activation of either ERK1/2 or ERK5 MAP kinase pathways can lead to disruption of the actin cytoskeleton. J Cell Sci 2005, 118:1663-1671

31. Ward Y, Wang W, Woodhouse E, Linnoila I, Liotta L, Kelly K: Signal pathways which promote invasion and metastasis: critical and distinct contributions of extracellular signal-regulated kinase and Ralspecific guanine exchange factor pathways. Mol Cell Biol 2001, 21:5958-5969

32. Krishnan K, Bruce B, Hewitt S, Thomas D, Khanna C, Helman LJ: Ezrin mediates growth and survival in Ewing's sarcoma through the AKT/mTOR, but not the MAPK, signaling pathway. Clin Exp Metastasis 2006, 23:227-236

33. Kansara M, Thomas DM: Molecular pathogenesis of osteosarcoma. DNA Cell Biol 2007, 26:1-18 
34. Gorlick R, Anderson P, Andrulis I, Arndt C, Beardsley GP, Bernstein M, Bridge J, Cheung NK, Dome JS, Ebb D, Gardner T, Gebhardt M, Grier H, Hansen M, Healey J, Helman L, Hock J, Houghton J, Houghton P, Huvos A, Khanna C, Kieran M, Kleinerman E, Ladanyi M, Lau C, Malkin D, Marina N, Meltzer P, Meyers P, Schofield D, Schwartz C, Smith MA, Toretsky J, Tsokos M, Wexler L, Wigginton J, Withrow S, Schoenfeldt M, Anderson B: Biology of childhood osteogenic sarcoma and potential targets for therapeutic development: meeting summary. Clin Cancer Res 2003, 9:5442-5453

35. Li J, Smyth P, Flavin R, Cahill S, Denning K, Aherne S, Guenther SM, O'Leary $\mathrm{JJ}$, Sheils O: Comparison of miRNA expression patterns using total RNA extracted from matched samples of formalin-fixed paraffin-embedded (FFPE) cells and snap frozen cells. BMC Biotechnol 2007, 7:36

36. Xi Y, Nakajima G, Gavin E, Morris CG, Kudo K, Hayashi K, Ju J: Systematic analysis of microRNA expression of RNA extracted from fresh frozen and formalin-fixed paraffin-embedded samples. RNA 2007, 13:1668-1674

37. Glud M, Klausen M, Gniadecki R, Rossing M, Hastrup N, Nielsen FC Drzewiecki KT: MicroRNA expression in melanocytic nevi: the usefulness of formalin-fixed, paraffin-embedded material for miRNA microarray profiling. J Invest Dermatol 2009, 129:1219-1224

38. Hunter KW: Ezrin, a key component in tumor metastasis. Trends Mol Med 2004, 10:201-204

39. Elliott BE, Meens JA, SenGupta SK, Louvard D, Arpin M: The membrane cytoskeletal crosslinker ezrin is required for metastasis of breast carcinoma cells. Breast Cancer Res 2005, 7:R365-R373

40. Weng WH, Ahlen J, Astrom K, Lui WO, Larsson C: Prognostic impact of immunohistochemical expression of ezrin in highly malignant soft tissue sarcomas. Clin Cancer Res 2005, 11:6198-6204

41. Khanna C, Wan X, Bose S, Cassaday R, Olomu O, Mendoza A, Yeung C Gorlick R, Hewitt SM, Helman LJ: The membrane-cytoskeleton linker ezrin is necessary for osteosarcoma metastasis. Nat Med 2004, 10:182-186

42. Griffiths-Jones S, Grocock RJ, van Dongen S, Bateman A, Enright AJ: miRBase: microRNA sequences, targets and gene nomenclature. Nucleic Acids Res 2006, 34:D140-D144
43. Krek A, Grun D, Poy MN, Wolf R, Rosenberg L, Epstein EJ, MacMenamin P, da Piedade I, Gunsalus KC, Stoffel M, Rajewsky N: Combinatorial microRNA target predictions. Nat Genet 2005, 37:495500

44. Lewis BP, Shih IH, Jones-Rhoades MW, Bartel DP, Burge CB: Prediction of mammalian microRNA targets. Cell 2003, 115:787-798

45. Folio C, Mora MI, Zalacain M, Corrales FJ, Segura V, Sierrasesumaga L, Toledo G, San-Julian M, Patino-Garcia A: Proteomic analysis of chemonaive pediatric osteosarcomas and corresponding normal bone reveals multiple altered molecular targets. J Proteome Res 2009, 8:3882-3888

46. Meng Y, Lu Z, Yu S, Zhang Q, Ma Y, Chen J: Ezrin promotes invasion and metastasis of pancreatic cancer cells. J Transl Med 2010, 8:61

47. Bacci G, Briccoli A, Ferrari S, Longhi A, Mercuri M, Capanna R, Donati D, Lari S, Forni C, DePaolis M: Neoadjuvant chemotherapy for osteosarcoma of the extremity: long-term results of the Rizzoli's 4th protocol. Eur J Cancer 2001, 37:2030-2039

48. Bielack SS, Kempf-Bielack B, Delling G, Exner GU, Flege S, Helmke K, Kotz R, Salzer-Kuntschik M, Werner M, Winkelmann W, Zoubek A, Jurgens $\mathrm{H}$, Winkler K: Prognostic factors in high-grade osteosarcoma of the extremities or trunk: an analysis of 1,702 patients treated on neoadjuvant cooperative osteosarcoma study group protocols. J Clin Oncol 2002, 20:776-790

49. Provisor AJ, Ettinger LJ, Nachman JB, Krailo MD, Makley JT, Yunis EJ, Huvos AG, Betcher DL, Baum ES, Kisker CT, Miser JS: Treatment of nonmetastatic osteosarcoma of the extremity with preoperative and postoperative chemotherapy: a report from the Children's Cancer Group. J Clin Oncol 1997, 15:76-84

50. Souhami RL, Craft AW, Van der Eijken JW, Nooij M, Spooner D, Bramwell VH, Wierzbicki R, Malcolm AJ, Kirkpatrick A, Uscinska BM, Van Glabbeke M, Machin D: Randomised trial of two regimens of chemotherapy in operable osteosarcoma: a study of the European Osteosarcoma Intergroup. Lancet 1997, 350:911-917 